\title{
Absence of the aortic valve cusps with mitral atresia, normal left ventricle, and intact ventricular septum
}

\author{
A Cabrera, J M Galdeano, E Pastor
}

\begin{abstract}
A case of a previously unreported anomaly is presented in which absence of the aortic valve cusps, mitral atresia, a normal left ventricle, and an intact ventricular septum were diagnosed by cross sectional echocardiography. The development of a normal left ventricle, rather than the hypoplastic ventricle usually associated with mitral atresia, is explained by filling of the ventricular cavity via the regurgitant aortic valve.
\end{abstract}

Absence of the aortic valve cusps with a normal aortic root is a very rare anomaly. To our knowledge only three cases have been reported. ${ }^{1-3}$ A hypoplastic left ventricle was found in all three cases; and in two there was a double outlet right ventricle. One case was diagnosed in life by cross sectional echocardiography. This report describes a case of absence of the aortic valve cusps with a normal left ventricle, mitral atresia, and enlarged ascending aorta that was diagnosed by cross sectional echocardiography and confirmed at necropsy.

Absence of the aortic valve cusps in association with a normal left ventricle has not previously been reported.

\section{Case report}

A baby weighing $3.5 \mathrm{~kg}$ was admitted to hospital when he was 12 hours old because of respiratory distress. He was the first son of healthy parents. Pregnancy was uneventful and he was delivered by caesarean section. Apgar scores at 1 minute and 10 minutes were 5 and 10 respectively.

On admission the baby had mild respiratory distress ( 60 breaths/min), cyanosis, and a heart rate of 160 beats $/ \mathrm{min}$. The axillary and femoral pulses were normal. He had a systolic-diastolic murmur that was heard best at the left upper sternal edge. Blood pressure was 70/40 $\mathrm{mm} \mathrm{Hg}$. The liver was not enlarged. A chest $x$ ray showed cardiomegaly with dilatation of the right atrium and ascending aorta. The lung fields were normal. The electrocardiogram showed a $Q R S$ axis at -50 with left ventricular hypertrophy and alteration of repolarisation. Cross sectional echocardiography showed left ventricular enlargement with an increase in wall thickness and immobile papillary muscles.
The ascending aorta was very dilated $(1.4 \mathrm{~cm}$ in diameter) and the aortic valve cusps could not be found (fig 1). The pulmonary trunk was dilated with a dysplastic pulmonary valve. Saline was injected through a catheter inserted into the aortic arch via the umbilical artery and bubbles passed to the left ventricle.

The patient became increasingly ill and died when he was 24 hours old. The necropsy showed the following: the heart had a normal atrial arrangement; the pulmonary veins drained normally into the left atrium and the foramen ovalis was patent. The mitral valve was atretic with an imperforate valve membrane and a concordant atrioventricular connection but papillary muscles and chordae were present (figure $2 a$ ). The three aortic valve cusps were absent (figure $2 b$ ) but the coronary sinuses were normal although the aortic root was small. The size of the left ventricle was normal for the age of the patient. The ascending aorta was dilated and a ductus arteriosus was present. The pulmonary valve had three cusps, each showing some myxoid dysplasia.

\section{Discussion}

Patients who have situs solitus, two ventricles, a concordant ventriculoarterial connection, and atresia of the left atrioventricular valve usually have a normal aortic valve and a ventricular septal defect. ${ }^{4-7}$ Mitral atresia is caused by an imperforate valve membrane at

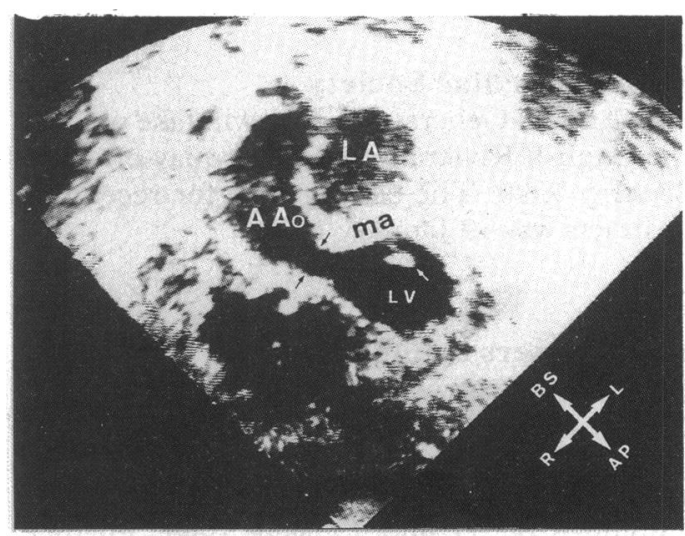

Figure 1 Cross sectional echocardiogram in subcostal long axis view showing a left ventricle with a cavity of normal size but with increased wall thickness. The ascending aorta was dilated and the aortic ring was small. The aortic valves were not seen in systole or in diastole. $L V$, left ventricle; $A$ Ao, ascending aorta; $L A$, left atrium; ma, atretic mitral valve. The black arrow indicates the valve ring and the white arrows the papillary muscle. AP, apex; $B S$, base. 
Figure 2 (a) A small left atrium with mitral valve atresia. The pulmonary veins were correctly connected. The foramen ovale was patent. $F O$, foramen ovale. The black arrows + ma indicate the atretic mitral valve. (b) Absence of the aortic valve cusps with a normal sized left ventricle and intact ventricular septum. Both coronary arteries were present. $A b$ + black arrows indicate the absence of aortic valve cusps. A Ao, ascending aorta.

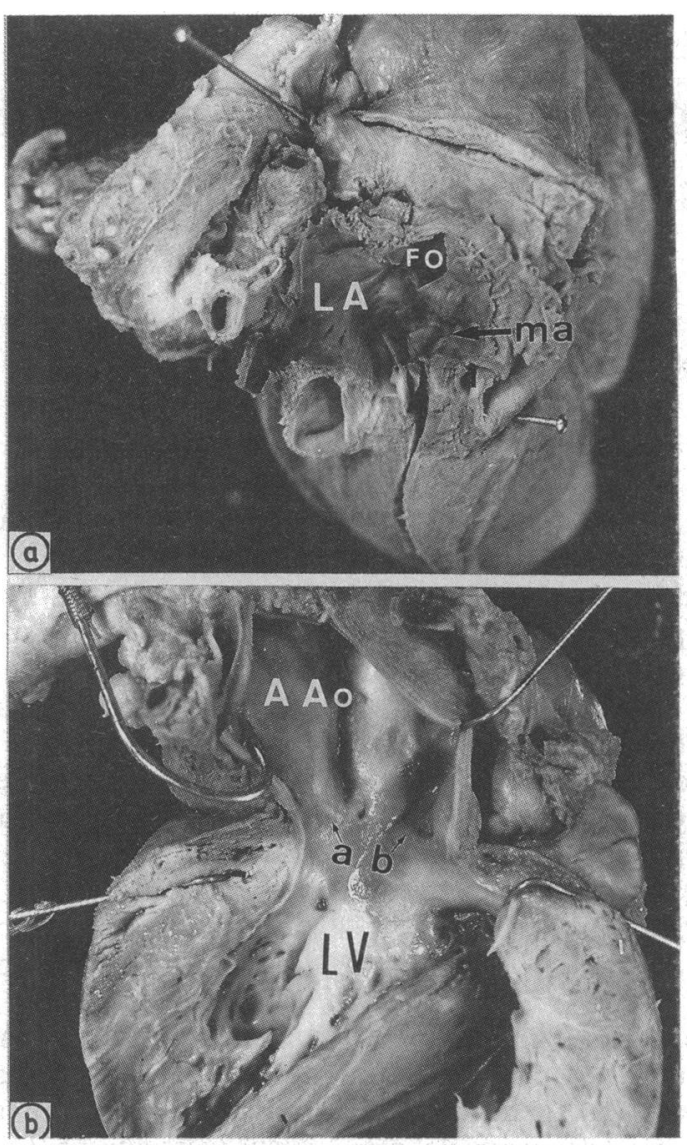

the cusp level. If the interventricular septum is intact the left ventricle is hypoplastic because it is not filled by blood from the right side or from the aortic root. The size of the left ventricle, however, is normal when there is regurgitation of the aortic valve. This regurgitation can be caused by a malfunctioning of the aortic valve cusps or by their absence, as in our case. When the patient was examined by cross sectional echocardiography the aortic valve cusps were not found and no echoes were detected in the zone of the valve ring. The coronary ostia were correctly situated in the left and right sinuses.

In cases of mitral atresia in which no septal defect is shown and the left ventricular cavity is well developed, aortic regurgitation should be suspected and can be confirmed by either continuous flow Doppler or saline contrast echocardiography after injection into the aortic root.

1 Toews WH, Lortscher RH, Keleminson LL. Double outlet right ventricle with absent aortic valve. Chest 1975; 68:381-2.

2 Bierman FZ, Yeh MN, Swersky S, Martin E, Wigger JH, Fox $\mathrm{H}$. Absence of the aortic valve-antenatal and postnatal two-dimensional and Doppler echocardiographic features. J Am Coll Cardiol 1984;3:833-7.

3 Rossi MB, Ho SY, Tasker TC. Absent aortic valve leaflets. Int J Cardiol 1986;11:235-7.

4 Cabrera A, Irurita M, Lekuona I, et al. Atresia mitral. Estudio anatómico e implicaciones quirúrgicas. Ann Esp

5 Moreno F, Quero M, Pérez-Diaz L. Mitral atresia with normal aortic valve. A study of eighteen cases and review of the literature. Circulation 1976;55:1004-10.

6 Thiene G, Daliento L, Frescura C, De Tommasi M, Macartney FJ, Anderson RH. Atresia of left atrioventricular orifice. Anatomical investigation in 62 cases. Br Heart $J$ 1981;45:393-401.

7 Gittenberger-de Groot AC, Wenink ACG. Mitral atresia. Morphological details. Br Heart J 1984;51:252-8.

\section{British Cardiac Society}

The Annual General Meeting will take place at the English Riviera Centre, Torquay on 22 to 25 May 1990. The closing date for receipt of abstracts was 19 January 1990.

\section{Pulsed lasers in angioplasty}

An international workshop on Pulsed Lasers in Angioplasty will be held under the auspices of the European Society of Cardiology working group of coronary flow and angina pectoris in Tübingen on 11 and 12 May 1990. Further information from Dr K R Karsch, Department of Cardiology, Medical Clinic, University of Tübingen, Otfried-Müller-Strasse 10, D-7400 Tübingen, Federal Republic of Germany.

\section{Biomechanics}

The 7th meeting of the European Society of Biomechanics will take place in Aarhus on 8 to 11 July 1990. For further information contact Biomechanics Laboratory, Orthopaedic Hospital, Randersvej 1, DK-8200 Aarhus N, Denmark; phone +458616 7500, extension 4649; fax +4586107733 . 